\title{
A APATIA SOBRENATURAL E A VONTADE DE SENTIDO: PASCAL E FRANKL
}

\author{
The supernatural apathy and the will to meaning: \\ Pascal and Frankl
}

\section{Carlos Frederico Lauer Garcia*}

\section{RESUMO}

Neste trabalho, apresentamos um paralelo entre Blaise Pascal e Viktor Frankl a partir da comparação entre a finitude da compreensão humana e o desejo humano de um sentido infinito. Num primeiro momento, trataremos da expressão "apatia sobrenatural" em Pascal. Em seguida, apresentaremos a relação, ainda em Pascal, entre o sofrimento e a perturbação dessa apatia. Com relação a Frankl, examinaremos primeiramente a relação entre sentido e transcendência, mesmo no sofrimento. A partir daí, concluiremos com a questão de um sentido infinito. Ao longo do texto, proporemos um diálogo entre nossos autores, principalmente a partir da segunda parte.

Palavras-chave: Apatia. Sentido da vida. Sentido infinito. Sofrimento. Transcendência. Vontade de sentido.

\section{ABSTRACT}

In this paper, we present a parallel between Blaise Pascal and Viktor Frankl from the comparison between the finitude of human understanding and the human desire for infinite meaning. In a first moment, we will discuss the term "supernatural apathy" in Pascal. Then, we will present the connection, still in Pascal, between the suffering and the perturbation of this apathy. With regard to Frankl, we will examine firstly the connection between meaning and transcendence, still in the suffering. From then on, we will conclude with the question of a infinite meaning. In the course of the paper, we will propose a dialogue between our authors, mainly from the second part.

Keyworks: Apathy. Meaning of life. Infinite meaning. Suffering. Transcendence. Will to meaning.

* Doutorando em Filosofia pelo Programa de Pós-Graduação em Filosofia da PUCRS.

\begin{tabular}{|l|l|l|l|l|l|}
\hline Teocomunicação & Porto Alegre & v. 44 & n. 3 & p. 396-417 & set.-dez. 2014 \\
\hline
\end{tabular}




\section{Introdução}

Blaise Pascal e Viktor Frankl são dois autores que, entre uma longa série que inclui nomes como Santo Agostinho (em oposição a Pelágio), Kierkegaard (em oposição a Hegel) e Dostoiévski (em oposição aos niilistas russos), perceberam, cada qual em seu contexto - Pascal em oposição a qualquer pretensão de autonomia da razão e Frankl em oposição a qualquer reducionismo do ser humano, seja em seu aspecto biológico, sociológico ou psicológico -, a necessidade de conceber o ser humano a partir de uma abertura para o eterno.

$\mathrm{O}$ que propomos aqui é estabelecer um paralelo entre Pascal e Frankl a partir da questão do sentido da existência como um problema primário do ser humano e, entretanto, definitivamente insolúvel em termos discursivos, mas apenas existenciais. Afinal de contas, se por sentido entendemos, como Frankl, "o que se tenciona, seja por uma pessoa que me pergunta algo, seja por uma situação que encerra uma pergunta e clama por resposta", 1 então é bastante fácil compreender que a respeito de cada situação que se inicia e se encerra, ou seja, para cada situação vivida, podemos com sucesso investigar tanto o sentido da situação como se houve um sentido realizado. Mas, não pode ser esse o caso quando se pergunta pelo sentido da própria vida, uma vez que a respeito dela não temos conhecimento exato de seu início, nem muito menos de seu fim. E, entretanto, sem o início e o fim da vida, permanecemos em um "vasto meio, sempre incertos e vacilantes", ${ }^{2}$ para usarmos os termos de Pascal.

Em um primeiro momento, procuraremos expor o problema em Pascal a partir da expressão "apatia sobrenatural", utilizada para descrever o estado do sujeito que se mantém indiferente a esse problema. Em seguida, atentaremos um pouco para a temática do sofrimento em Pascal - na forma de enfermidade -, encarando-a como um modo de tornar-se sensível para a morte e, portanto, para o problema da finitude da vida, ao mesmo tempo em que faz surgir um desgosto pelos bens relacionados ao divertissement, isto é, aqueles que desviam o ser humano da consideração da possibilidade de bens perpétuos.

1 FRANKL, Viktor. $A$ vontade de sentido: fundamentos e aplicações da logoterapia. 2. ed. São Paulo: Paulus, 2013, p. 81.

2 Laf. 199. 
Em um segundo momento, começaremos expondo a relação entre sentido e autotranscendência em Frankl, com o objetivo de enfatizar que, tal como em Pascal, a realização humana consiste primariamente em um esquecimento do eu que, em seu termo, permite que se fale em aniquilação. Em seguida, abordaremos a questão do sentido no sofrimento, buscando ressaltar uma decisão última que garante a integridade e responsabilidade humana mesmo nas situações mais calamitosas. A partir daí, finalmente, consideraremos a relação entre o ser humano em sua profundidade - mediante o conceito de coração em Pascal - e a questão de um sentido infinito, levantada por Frankl.

\section{A apatia sobrenatural}

A tensão entre o finito e o infinito é uma das mais acentuadas características da antropologia pascaliana. De fato, toda perturbação do ser humano que se depara com "infinidades por todas as partes", 3 incapaz, portanto, de estabelecer o seu lugar próprio na natureza, é uma perturbação própria de um ser "que não é produzido senão para o infinito". ${ }^{4}$ Essa diferença radical entre a condição do ser humano e o seu fim último se faz notar tanto na ordem racional quanto na ordem volitiva. Tal distinção é fundamental para nosso propósito, pois é a partir dela que poderemos entender em que consiste a apatia que é objeto de repreensão por parte de Pascal. Primeiramente, porém, citemos um fragmento que está entre os mais elucidativos do problema com o qual ora nos ocupamos:

Pois enfim o que é o homem na natureza? Um nada em relação ao infinito, um tudo em relação ao nada, um meio entre nada e tudo, infinitamente distante de compreender os extremos; o fim das coisas e seus princípios estão para ele invencivelmente escondidos num segredo impenetrável. ${ }^{5}$

Quando Pascal procura descrever qualquer aspecto da miséria humana -e, nesse caso, por enquanto, estamos diante da miséria cognitiva -, a sua retórica não costuma se valer de amenizações: se os extremos da realidade estão infinitamente distantes de nossa compreensão, isso

\footnotetext{
3 Laf. 427.

4 PASCAL, B. Oeuvres complètes. Organização por Louis Lafuma. Paris: Seuil, 1963. p. 231.

5 Laf. 199.
} 
significa - para não recorrer a outra linguagem que não a propriamente pascaliana - que não há proporção entre a compreensão humana e a estrutura da realidade. ${ }^{6}$ Recorrendo ao fragmento no qual Pascal expõe de maneira mais acentuada a heterogeneidade entre as ordens da realidade, podemos dizer que do mesmo modo que "de todos os corpos juntos, não se poderia chegar a um pequeno pensamento", 7 tampouco a razão, na excelência de seu exercício, poderia julgar a realidade em sua totalidade. Ao contrário, a razão chega a seu limite justamente em reconhecer que há uma infinidade de coisas que a ultrapassam. ${ }^{8}$ Desse modo, é compreensível que se acuse de soberba a razão que pretenda estender o seu julgamento para além de uma realidade ${ }^{9}$ parcial, ou seja, a razão que pretenda operar fora de sua ordem: é justamente o conceito de tirania em Pascal. ${ }^{10}$ Bastante significativo, ademais, é que a acusação de soberba encontre um contexto no qual se insere o problema do "princípio das coisas": "É uma coisa estranha que eles [os homens] tenham querido compreender os princípios das coisas e de aí chegar até conhecer tudo, por uma presunção tão infinita quanto seu objeto".

É justo, portanto, que a razão, assim, desordenada, sofra, sobretudo num contexto apologético, um processo de humilhação, pelo qual virá a conhecer seus limites. Pascal não hesita em expressar o seu agrado ao "ver essa soberba razão humilhada e suplicante". ${ }^{11}$ É a isso que se deve, principalmente, o flerte do jansenista com o pirronismo em diversas passagens dos Pensées, ${ }^{12}$ bem como o seu elogio a Montaigne na Entretien avec M. de Saci. Se "Deus deve reinar sobre tudo, e tudo se relacionar com Ele", ${ }^{13}$ como diz o outro fragmento

6 Sabemos, porém, que Pascal vai muito mais longe, chegando a identificar a desproporção na mesma ordem da natureza. É justamente o caso do fragmento dos dois infinitos, ao qual pertence a passagem citada. Todavia, como nosso objetivo é encaminhar a discussão para o sentido último da vida humana no sobrenatural, deixaremos de lado o aspecto da desproporção interna à própria natureza. Ao leitor interessado nesse ponto, remetemos a PONDÉ, L. F. O homem insuficiente: comentários da antropologia pascaliana. São Paulo: EDUSP, 2001, especialmente p. 189-191.

7 Laf. 308.

8 Cf. Laf. 188.

9 Laf. 199.

${ }^{10}$ Cf. Laf. 110. E também Laf. 58: “A tirania consiste no desejo de dominação, universal e fora de sua ordem".

${ }^{11}$ Laf. 52.

12 A lista dessas ocorrências seria muito extensa, mas certamente uma das mais significativas encontramos em Laf. 691: "O pirronismo é o verdadeiro, pois, afinal de contas, os homens, antes de Jesus Cristo, não sabiam onde estavam, nem se eram grandes ou pequenos [...]”.

${ }^{13}$ Laf. 933. 
acerca das três ordens, então humilhar a razão consiste em orientá-la para aquilo que a ultrapassa, isto é, em última instância, o seu próprio Criador.

Com isso, porém, o que se busca não é uma atitude irracionalista da fé $^{14}$ - o flerte de Pascal é apenas parcial -, mas antes uma compreensão do ato de fé dentro do qual a razão tenha o seu exercício legítimo. Ora, para Pascal, não apenas a atitude de "asseverar, quando necessário", mas também a atitude de "submeter-se, quando necessário"15 são próprias de uma razão em seu legítimo exercício. Como tudo na antropologia pascaliana, esse cuidado remonta à questão da atuação do homem em pecado, portanto, à questão da concupiscência e, nesse caso específico, à concupiscência do espírito, que recebe o nome de curiosidade. Essa última consiste na pretensão de autonomia da ordem racional, o que culmina na separação entre a ciência e a moral, mediante a incapacidade do homem em se encontrar em meio à diversidade que é objeto mesmo de sua curiosidade: "Pois uma só coisa é necessária, e nós amamos a diversidade". ${ }^{16} \mathrm{O}$ ceticismo aparece como o fim de tal pretensão, portanto, como o seu fracasso: "É assim que ele [Montaigne] repreende tão forte e cruelmente a razão desprovida da fé, a ponto de fazer-lhe duvidar se ela é racional, e se os animais o são ou não [...]". ${ }^{17}$ Toda pretensão humana de estabelecer os seus fundamentos fora de uma convergência para o sobrenatural resulta também em Pascal em uma dissolução tanto do conhecimento que o ser humano possa ter de si mesmo quanto em uma dissolução propriamente ontológica:

A curiosidade impele a estudar coisas não abstratas nelas mesmas, mas que fazem abstração do conhecimento de si. Ora, não tomando por base esse primeiro conhecimento, o homem corre o risco de se ver dispersado, dissipado por uma multidão de ciências diferentes, sem linha entre elas. A curiosidade é, assim, prejudicial tanto porque ela afasta

\footnotetext{
${ }^{14}$ É sempre uma advertência pertinente a de que Pascal não adota uma postura antifilosófica. Os "meios de crer" não deixam dúvida quanto a isso: "[...] é necessário abrir o espírito às provas [...]”. Cf., ademais, Cf. MICHON, H. L'ordre du coeur: philosophie, théologie et mystique dans les Pensées de Pascal. Paris: Honoré Champion, 1996, p. 115: “[...] Pascal não recusa o trabalho da razão, o que seria o ponto de vista de um antifilósofo, ele contesta ao contrário a possibilidade de um discurso da razão pura, quer dizer, da razão constituída em única autoridade, privada da luz da fé".

${ }^{15}$ Laf. 268.

${ }^{16}$ Laf. 270. Note-se simultaneidade, uma das mais comuns em Pascal, entre o problema do conhecimento e o do bem verdadeiro. A esse respeito, cf. RUSSIER, J. La foi selon Pascal: Dieu sensible au coeur. Paris: PUF, 1949, p. 51-52.

${ }^{17}$ PASCAL, 1963, p. 294.
} 
o homem do conhecimento dele mesmo quanto porque ela impede de unificar seu saber. ${ }^{18}$

Todavia, se, por um lado, é denunciada a presunção da razão em estender o seu domínio para além do empírico e do infinito que lhe são próprios, ${ }^{19}$ por outro lado, de maneira nenhuma a totalidade humana é encerrada em sua ordem racional. Permanece no ser humano o desejo daquilo mesmo que ultrapassa infinitamente a razão, isso é, o desejo de um bem para além dos bens particulares: "Eles compreenderam que o verdadeiro bem devia ser tal que todos pudessem possuí-lo ao mesmo tempo sem diminuição e sem inveja, e que ninguém pudesse perdêlo contra a sua vontade". ${ }^{20}$ Acrescente-se a esse último critério para a distinção do verdadeiro bem - que não se pode perder contra a vontade - o de que deve resultar em uma felicidade tão durável quanto a própria alma imortal. ${ }^{21}$

Sofreria esse desejo do infinito a mesma condenação que a razão que pretende fazer-se infinita? De jeito nenhum, pois a infinidade é a constituição mesma do ser humano, mas - e aqui a tensão a qual aludimos inicialmente aparece em sua forma mais veemente - tratase de um "abismo infinito" que só pode ser preenchido por um objeto infinito e imutável", ${ }^{22}$ o qual, todavia, falta ao homem desde o pecado. Esse último deu origem a uma queda, mas uma queda incompleta, que lança o ser humano meio-termo entre a presença e a ausência de seu fim último: "O que aí aparece não marca nem uma exclusão total, nem uma presença manifesta da divindade, mas a presença de um Deus que se esconde. Tudo traz esse caráter". ${ }^{23}$

${ }^{18}$ MICHON, 1996, p. 35. A respeito da contribuição que Pascal encontra no pirronismo, conferir RUSSIER, J, 1949, p. 53: "Dito de outro modo, desde que a razão der a si mesma uma explicação e uma justificação autônoma, construir um sistema, em lugar de se contentar com certezas elementares que a natureza nos tem providenciado, tenta elaborar uma teoria do conhecimento que baste a si mesma, o pirronismo está aí para lhe mostrar a vaidade de seu empreendimento: toda pretensão de filosofar, e de filosofar sem a fé, termina necessariamente nele, e isso nos adverte não de que é necessário deter-se nele, mas de que, tendo tomado um mau caminho, nós devemos voltar atrás e pôr de outro modo o problema humano".

${ }^{19}$ Cf. MICHON, 1996, p. 204.

${ }^{20}$ Laf. 148.

${ }^{21}$ Sur la conversion du pécheur. PASCAL, 1963, p. 290.

${ }^{22}$ Laf. 148. Sobre a relação entre os últimos fragmentos citados, cf. LACOMBE, L'Apologétique de Pascal: étude critique. Paris: PUF, 1958, p. 156.

${ }^{23}$ Laf. 449. Cf. também MICHON, 1996, p. 272: "Pois o que é o desejo, senão aquele estado intermediário entre a presença e a ausência, entre a posse e a privação?" 
Aparece aqui, de maneira bastante clara, como a temática do desejo insatisfeito do ser humano remete à temática do Deus absconditus. Ora, a busca por esse Deus não será em nenhum momento condenada como soberba, mas será antes critério de sensatez: “[...] há apenas dois tipos de pessoas que se podem chamar de razoáveis: aqueles que servem Deus de todo seu coração após tê-Lo encontrado e aqueles que $\mathrm{O}$ procuram de todo coração porque eles ainda não $\mathrm{O}$ conhecem". ${ }^{24}$

Conforme Pascal expõe em outro pensamento, ${ }^{25}$ há uma terceira categoria a ser considerada: a dos que nem buscam Deus, nem $\mathrm{O}$ encontram. ${ }^{26} \mathrm{~A}$ indignação de Pascal para com esses últimos ultrapassa em muito sua zombaria para com a razão que não se submeta aos seus limites. Aos que vivem indiferentes - ou, pelo menos, tentam manterse indiferentes - frente à mesma dúvida que abala os que já não se conformam com a satisfação dos desejos concupiscentes, embora ainda não tenham descoberto nada mais sólido, isto é, frente à dúvida forçosamente posta pela antevisão de um fim próximo e inevitável como a morte, Pascal reserva uma mistura de ira e desprezo pelo que ele chama de "apatia sobrenatural":

Nada é tão importante para o homem quanto seu estado; nada lhe é tão temível como a eternidade. Assim, não há nada de natural em se encontrar homens indiferentes quanto à perda de seu ser e quanto ao perigo de uma eternidade de misérias. Eles são bem diferentes a respeito de todas as outras coisas: temem até as mais leves, eles as preveem, eles as sentem; e esse mesmo homem que passa tantos dias e noites enfurecido e desesperado pela perda de um cargo, ou por qualquer imaginária ofensa à sua honra, esse mesmo homem sabe que vai perder tudo com a morte, e permanece sem inquietação e sem emoção. É uma coisa monstruosa ver num mesmo coração, e ao mesmo tempo, essa sensibilidade pelas menores coisas e essa estranha insensibilidade pelas

${ }^{24}$ Laf. 427. A exigência de que a busca seja "de todo coração" é muito significativa no contexto apologético. À vontade corrompida pelo pecado basta a menor das distrações para que se desvie de seu desejo por Deus. Nesse caso, a sinceridade com que se busca corresponde a preferir o tormento de nada encontrar à tranquilidade sempre ameaçada do divertissement. Cf. RUSSIER, 1949, p. 177-178.

25 Laf. 160.

${ }^{26}$ Interessante perguntar se haveria a possibilidade de um quarto grupo: o dos que conhecem Deus sem O ter buscado. Ora, o contexto da gratuidade da graça, no qual Pascal está submerso, parece dever incluir essa possibilidade, de uma inclinação do coração sem uma busca prévia. É talvez o que se exponha em Laf. 380. Cf. também RUSSIER, 1949, p. 195-198. 
maiores. É um encantamento incompreensível, uma apatia sobrenatural, sinal de uma força todo-poderosa que o causa. ${ }^{27}$

Ora, a ausência de dúvida em questão se refere, como procuramos encaminhar logo em nossa primeira citação, ao "fim último da vida". ${ }^{28}$ Se, anteriormente, Pascal tomava como causa de perturbação a incompetência do ser humano frente ao conhecimento dos extremos da natureza, é agora seus próprios extremos que lhe escapam. É, pois, a respeito do problema da totalidade de sua própria vida que Pascal não compreende a atitude da "tão extravagante criatura" que se mantenha "tranquila e satisfeita". Sabemos de antemão, portanto, que a busca que Pascal entende ser a mais conforme a nós não é própria da investigação racional, uma vez que seu resultado sequer pode ter proporção com a razão. De fato, Pascal alerta repetidamente que a busca do homem por Deus deve ser de "todo seu coração" e não com toda força de sua razão. ${ }^{29}$

Talvez a indignação do jansenista não fosse tão grande se a apatia fosse estendida por todas as questões da vida, as menores e as maiores. $\mathrm{O}$ que surpreende, porém, é uma mesma disposição distribuída de forma tão injusta: a aflição pela perda do cargo ou da honra e a tranquilidade diante da perda da própria vida. Ora, o mesmo amor próprio que desencadeia a primeira preocupação, deveria com muito mais intensidade desencadear a segunda, por um mero senso de proporções. A busca por um bem mais sólido que um cargo ou a honra deve-se dar pelo simples "interesse de amor-próprio", o qual, presente em tudo o mais, parece estranhamente não ter o seu efeito sobre uma questão tão decisiva. Mais do que isso, manter-se "tranquilo e satisfeito" diante da morte iminente é apenas o aspecto negativo - ausência de sentimento - do incrédulo. É preciso ter em conta que a descrição de Pascal acrescenta: "[...] se ele professa tais coisas, e se ele enfim faz disso objeto de sua alegria e de sua

\footnotetext{
${ }^{27}$ Laf. 427. A expressão que é aqui traduzida por apatia é assoupissement, que, mais naturalmente deveria ser traduzida por adormecimento. A nossa escolha por essa tradução se deve a dois motivos principais: em primeiro lugar, apatia está mais próxima de tédio, conceito fundamental na dinâmica do homem incapaz de aquietar-se com os bens mundanos; em segundo lugar, se o homem que se enfurece pela perda de um cargo sabe que vai perder esse tal cargo e tudo o mais com a morte, a sua condição não parece ser exatamente a de um adormecido, portanto, inconsciente de sua realidade, mas, justamente, a de um apático frente a essa realidade que ele não ignora, apesar de manter-se insensível. Ademais, Sérgio Milliet, in: PASCAL, Blaise. Pensamentos. São Paulo: Difusão Europeia do Livro, 1961, p. 101, opta pelo termo apatia.

${ }^{28}$ Laf. 427.

${ }^{29}$ Cf., no contexto dos Pensées Laf. 427, Laf. 149 e Laf. 269.
} 
vaidade [...]". ${ }^{30}$ Tais atitudes tornam difícil pensar aqui em uma mera visão restrita das coisas: o problema da morte não é ignorado, mas rejeitado. Nessa sua forma mais radical, a apatia aparece como a atitude deliberada de se recusar a dar qualquer importância para o fim último da vida humana. ${ }^{31}$

Que a apatia seja qualificada como sobrenatural é bem justo, desde que tenhamos em conta não apenas a primazia da graça sobre o conhecimento mesmo do pecado, mas também a conformidade com a Sagrada Escritura. ${ }^{32}$ A respeito desse segundo aspecto, mais que apatia, ou adormecimento, o que é qualificado como sobrenatural é o que se pode traduzir por "cegueira" (aveuglement): "Se é uma cegueira sobrenatural viver sem procurar o que somos, é uma cegueira terrível viver mal crendo em Deus". ${ }^{33}$ Mas, aqui não parece se tratar meramente de um defeito no sentido da visão - o que, de certo modo, provocaria um paradoxo com a lucidez, referida acima, do incrédulo com respeito ao seu estado -, mas antes de algo mais próximo de uma obstinação ou de uma ilusão, uma obstinação na escuridão imposta ao pecador, que só pela graça pode dar-se conta da miséria em que se encerrou. ${ }^{34}$

Agora, se, por um lado, a evidência de uma morte iminente possa ser assim desconsiderada, por outro, a compreensão da finitude da vida deverá estar presente no rejeitado. Pode apenas ser desviado de sua causa mesma, Deus, para o finito:

Certamente, ele não pode não desejar, segundo as palavras de Pascal [Laf. 401], mas ele pode consentir ou não a esse desejo: aquele

${ }^{30}$ Laf. 427.

${ }^{31}$ Mais adiante no fragmento, a decisão pela indiferença é explicitada: "Tudo o que eu sei é que devo morrer logo; mas isso que eu mais ignoro é essa morte que eu não poderia evitar. Assim como não sei de onde venho, tampouco sei para onde vou; e eu sei somente que, saindo desse mundo, cairei para sempre no nada, ou nas mãos de um Deus irritado, sem saber para qual dessas duas condições eu devo ser entregue eternamente. Eis meu estado, pleno de fraqueza e de incerteza. E, de tudo isso, concluo que eu devo passar todos os dias de minha vida sem pensar em procurar o que me deve acontecer".

${ }^{32}$ Cf. Laf. 893.

${ }^{33}$ Laf. 623.

${ }^{34}$ Sobre as relações entre pecado (miséria) e cegueira, cf., por exemplo, Laf. 149: "[...] e eles estão submersos nas misérias de sua cegueira e de sua concupiscência [...]"; Laf. 198: "Vendo a cegueira e a miséria do homem [...]"; Laf. 502: "[...] uma cegueira semelhante àquela que a carne lança no espírito [...]". E, uma das mais significativas, Laf. 781: Ela [a Escritura] diz, ao contrário, que Deus é um Deus escondido e que, depois da corrupção da natureza, Ele os deixou numa cegueira da qual eles não podem sair senão por Jesus Cristo, fora do qual é tirada toda comunicação com Deus". 
que se diverte é aquele que, não consentido em desejar Deus, deseja todo o resto, quer dizer, todas as coisas. ${ }^{35}$

O divertimento, isto é, o desvio da consideração da realidade de nossa condição, é, de fato, posto em xeque pela evidência da morte. Trazer essa última forçosamente à memória, perturbando o costume de se deleitar nos bens particulares, é uma tarefa constante da apologética pascaliana. Averiguemos esse ponto.

\section{O costume perturbado}

A insensibilidade está entre os mais relevantes efeitos que Pascal atribui ao costume. Ora, no contexto que até agora formulamos, é certamente a insensibilidade com relação à morte que aparece como a mais relevante, ainda que indissociável de outros aspectos. Nesse sentido, a primeira coisa a se constatar é uma forte relação entre o costume e o divertimento: "[...] o divertimento nos distrai e nos faz chegar insensivelmente à morte". ${ }^{36}$ Mas, como faz isso, senão pela continuidade dos afazeres mais triviais, tais como "correr atrás de uma lebre"'? ${ }^{37}$ A eficácia do divertimento não depende tanto do tipo de objeto que diverte: "O homem, ainda que pleno da tristeza que seja, caso se consiga fazer com que ele entre em algum divertimento, ei-lo feliz durante esse tempo [...]". ${ }^{38}$ Ademais, uma vez que se interrompa o divertimento, "imediatamente, sairá do fundo de sua alma o tédio, a escuridão, a tristeza, a aflição, o rancor, o desespero". ${ }^{39}$ Pascal, de fato, parece não deixar uma terceira alternativa: "Sem divertimento, não há alegria; com divertimento, não há tristeza". ${ }^{40}$

Assim, a eficácia do divertimento depende da ilusão da perpetuidade daquilo que diverte, e essa ilusão, por sua vez, é enraizada mediante a repetição: "Quem demonstrou que amanhã será dia e que um dia morreremos? E haverá algo em que mais se acredite?". ${ }^{41}$ Desse modo, é fundamental para o apologista desfazer a ilusão da perpetuidade de nossos prazeres cotidianos e tornar sensível a morte, fim de todos os

\footnotetext{
${ }^{35}$ MICHON, 1996, p. 277.

${ }^{36}$ Laf. 414.

${ }^{37}$ Laf. 136.

${ }^{38}$ Laf. 136. Grifo nosso.

${ }^{39}$ Laf. 622. Grifo nosso.

${ }^{40}$ Laf. 136.

${ }^{41}$ Laf. 821.
} 
prazeres. Isso equivale a tornar sensível um grau maior de realidade: "Não há nada mais real do que isso, nem nada mais terrível". ${ }^{42}$

Todavia, a tarefa de tornar a morte sensível, com o objetivo de, por um lado, aniquilar o deleite causado pelos bens corriqueiros do divertimento e, por outro, despertar o anseio por bens eternos, não encontrará o seu êxito em meio ao raciocínio que envolva um senso de proporções entre as nossas preocupações cotidianas e a incerteza sobre a nossa condição futura, mas antes na experiência mesma que mais aproxima da morte, isto é, a enfermidade. À perspicácia de uma razão sã, contrapõe-se agora a humilhação de um corpo enfermo:

Vós me destes a saúde para vos servir, e eu fiz dela um uso todo profano. Vós me enviais agora a enfermidade para me corrigir: não permiti que eu a use para Vos irritar por minha impaciência. Eu usei mal minha saúde, e Vós muito justamente me punistes. [...]. Pois, Senhor, como no instante de minha morte eu me encontrarei separado do mundo, despido de todas as coisas, sozinho em Vossa presença, para responder à Vossa justiça por todos os movimentos de meu coração, fazei com que eu considere essa enfermidade como uma espécie de morte, separado do mundo, despido de todos os objetos de minhas afeições, sozinho em Vossa presença, para implorar por Vossa misericórdia a conversão de meu coração. ${ }^{43}$

A correção que Pascal entende ser o fim de seu sofrimento tem dois aspectos principais. Em primeiro lugar, trata-se de uma correção da afeição, que não mais pode ter como objeto aquilo que será destruído com a morte. Em segundo lugar, trata-se de uma correção propriamente intelectual, no sentido de compreender que não pode haver nada realmente digno de amor senão Deus. Compreende-se, portanto, a súplica de Pascal, nesse mesmo opúsculo: "Fazei-me a graça, Senhor, de reformar minha razão corrompida e de conformar meus sentimentos aos Vossos". ${ }^{44}$

${ }^{42}$ Laf. 427. Cf. também, FERREYROLLES, Gérard. Les Reines du monde: 1'imagination et la coutume chez Pascal. Paris: Honoré Champion Éditeur, 1995, p. 35: "Quando o cristão se fizer apologista, ele chamará o senso crítico de seu interlocutor para o convidar a suspender o encadeamento mortal do hábito. Dizer que 'é necessário viver de outro modo no mundo', dependendo se aí deveremos estar sempre ou 'se é certo que aí não estaremos por muito tempo e incerto se aí estaremos uma hora sequer' [Laf. 154], é interromper a fascinação de nosso primeiro hábito, que é esse de viver, pela consideração da morte, termo de todos os hábitos".

${ }^{43}$ Prière pour demander a Dieu le bon usage des maladies. PASCAL, 1963, p. 362-363.

${ }^{44}$ Ibidem, p. 364. 
A enfermidade aparece aqui, desse modo, não apenas como a justiça pelos pecados cometidos, mas como a graça de fazer sentir o desgosto pelo mundo, ao mesmo tempo em que se antevê bens antes tão insensíveis e distantes quanto a morte que agora os revela. Essa insensibilidade, por sua vez, antes de dar lugar à justa afeição pelo eterno, faz-se conhecer sob a forma de desgosto pelo perecível. Tratase claramente do processo de conversão, e é o que se descreve em outro opúsculo, muito semelhante a Prière sob diversos aspectos: "Por um lado, a presença dos objetos visíveis a toca [na alma] mais que a esperança dos invisíveis, e por outro, a solidez dos invisíveis a toca mais que a vaidade dos invisíveis". ${ }^{45}$

A antecipação da morte causa, pois, uma confusão - uma "santa confusão"46 - entre a nossa condição finita e o infinito que se faz sentir: a alma "reconhece a graça" que Deus lhe fez "de manifestar Sua infinita majestade a um vermezinho tão débil". ${ }^{47}$ Tal destruição da apatia sobrenatural pela graça sobrenatural abre, então, caminho para uma busca contínua pela conformação da criatura ao Criador, mediante a perseverança que renova sempre a sensibilidade de seu fim último, de modo que o hábito se converte em perseverança: "Uma continuação que não é continuidade, uma repetição que é renovamento, um deleite que cava o desejo que ele preenche: esse chefe de obra do hábito que é a perseverança final é um hábito ao qual não nos habituamos"48. Em suma, uma orientação para um Deus absconditus, "um Deus que se esconde para ser procurado". ${ }^{49}$

\section{Sentido e autotranscedência}

Em Pascal, o divertimento consiste, em termos teológicos, na tentativa - inevitavelmente frustrada - de satisfazer, mediante a conquista de bens particulares, uma vontade do infinito que permanece no ser humano desde a queda. Desse modo, essa constante frustração, ao mesmo tempo em que caracteriza a miséria do homem, é sinal de uma grandeza perdida. Viktor Frankl considera de maneira semelhante a consciência humana:

\footnotetext{
${ }^{45}$ Sur la conversion du pécheur. PASCAL, 1963, p. 290.

${ }^{46}$ Ibidem, p. 290.

47 Ibidem, p. 291.

${ }^{48}$ FERREYROLLES, 1995, p. 113-114.

${ }^{49}$ MICHON, 1996, p. 328.
} 
Da mesma maneira que o umbigo humano, considerado por si mesmo, pareceria sem sentido, porque só pode ser compreendido a partir da pré-história, ou melhor, da história pré-natal do homem, como sendo um "resto" no homem que o transcende e o leva à sua procedência do organismo materno, no qual estava contido, exatamente desta mesma forma a consciência só pode ser entendida em seu sentido pleno quando a concebermos à luz de uma origem transcendente. ${ }^{50}$

Algo no homem indica que há algo para além do homem. A busca por esse algo além de si mesmo, que serve para Pascal como critério de razoabilidade, conforme expusemos acima, é para Frankl critério mesmo de uma humanidade plena: "Ser humano é ser direcionado a algo que não a si mesmo". ${ }^{51}$ Ainda que não por esse nome, o tema da autotranscendência está claramente presente na análise pascaliana do divertimento, na medida em que o amor próprio é tanto mais satisfeito quanto mais o sujeito se diverte, isto é, se desvia de sua condição real. ${ }^{52} \mathrm{E}$ tanto mais se diverte quanto menos pensa no termo iminente de todo divertimento. Trata-se, em suma, de uma inversão que busca na natureza o que está direcionado infinitamente para além dela.

Essa mesma inversão Frankl aplica à consciência. E para nosso objetivo é muito relevante ter em conta que, para Frankl, "a consciência é um órgão de sentido. Ela poderia ser definida como a capacidade de procurar e descobrir o sentido único e exclusivo oculto em cada situação". ${ }^{53}$ Talvez mais significativo ainda é o fato de Frankl chamar de irreligioso o homem que não concebe uma instância superior à sua consciência, uma instância da qual a própria consciência seria não mais que porta-voz. ${ }^{54}$ Disso decorre - e o próprio Frankl assim explicita - que um critério da religiosidade é já a busca por um sentido. Daí Frankl reconhecer a religiosidade como algo de modo algum inato,

\footnotetext{
${ }^{50}$ FRANKL, Viktor. A presença ignorada de Deus. 7. ed. São Leopoldo: Sinodal; Petrópolis: Vozes, 1992, p. 41.

${ }^{51}$ FRANKL, 2013, p. 67.

${ }^{52}$ Cf. Laf. 978.

${ }^{53}$ FRANKL, 1992, p. 68.

${ }^{54}$ Ibidem, p. 42: "O homem irreligioso, portanto, é aquele que ignora esta transcendência da consciência. Com efeito, também o homem irreligioso 'tem' consciência, assim como responsabilidade; apenas ele não questiona além, não pergunta pelo que é responsável, nem de onde provém sua consciência”.
} 
mas sim primariamente humano, isto é, reconhecer no ser humano uma "religiosidade inconsciente". 55

Dado nosso objetivo geral, é um passo importante agora considerar que isso que Frankl entende ser a distinção humana por excelência, a sua autotranscendência, que redunda na busca por um sentido, pode ser frustrada, e a sua ausência sentida sob a forma de vazio existencial. A semelhança com Pascal não se dá unicamente por uma coincidência terminológica - à qual, aliás, deve-se acrescentar que o vazio existencial se manifesta sob a forma de tédio e apatia ${ }^{56}$-, mas pela análise mesma que Frankl faz do modo de expressão desse vazio existencial:

Existem ainda diversas máscaras e disfarces sob os quais transparece o vazio existencial. Às vezes, a vontade de sentido frustrada é vicariamente compensada por uma vontade de poder, incluindo sua mais primitiva forma, que é a vontade de dinheiro. Em outros casos, o lugar da vontade de sentido frustrada é tomado pela vontade de prazer. É por isso que, muitas vezes, a frustração existencial acaba em compensação sexual. Podemos observar nesses casos que a libido sexual assume proporções descabidas no vazio existencial. ${ }^{57}$

A frustração do sentido existencial, isto é, uma repressão da religiosidade inconsciente do ser humano, degenera - vemos aqui - na pretensão de fazer do poder ou da libido um absoluto que substitua a transcendência do sentido. Falamos acima da concupiscência do espírito e aludimos brevemente à relação entre concupiscência e cegueira (ou obstinação no pecado). Ora, nada mais próprio da concupiscência do que a cegueira para o que transcende o ser humano, isto é, em Pascal, "a concupiscência que o desvia de Deus". ${ }^{8}$ Ora, desviar é exatamente um sentido bastante próximo do divertissement, ${ }^{59}$ que desvia a nossa atenção do vazio interior a ser verdadeiramente preenchido por um sentido último, tão infinito quanto a vontade na qual deixou a marca de sua ausência, mas não a ausência de seu desejo. Temos, aqui, um dos

${ }^{55}$ Ibidem, p. 51: "Por conservar o caráter espiritual-existencial da religiosidade inconsciente, ao invés de atribuí-la à facticidade psicofísica, logicamente torna-se também impossível considerá-la como algo inato. Ao nosso parecer, a religiosidade não pode ser inata por não estar presa ao biológico".

${ }^{56}$ Cf. FRANKL, 2013, p. 107: “As principais manifestações de frustração existencial - tédio e apatia - têm se tornado um desafio, tanto para a educação quanto para a psicologia".

${ }^{57}$ FRANKL, Viktor. Em busca de sentido. Um psicólogo no campo de concentração. 25. ed. São Leopoldo: Sinodal; Petrópolis: Vozes, 2008, p. 132.

${ }^{58}$ Laf. 269. Grifo nosso.

${ }^{59}$ Cf. PONDÉ, L. F. O homem insuficiente: comentários da antropologia pascaliana. São Paulo: EDUSP, 2001, p. 7. 
aspectos mais fortemente agostinianos de Pascal, motivo pelo qual se torna muito significativa a seguinte alusão de Frankl: “[...] transcenderse a si mesma é um constitutivo da existência humana. Em termos agostinianos, poderíamos dizer que o coração do homem não descansa até que se encontre e se realize o sentido da vida". ${ }^{60}$

Agora, tal como foi o caso que pudemos ver em Pascal, o de não apenas ser como que despertado, pela enfermidade, de um sono concupiscente, mas vislumbrar um sentido nessa enfermidade, Frankl também investiga um sentido no sofrimento. Cabe-nos averiguar esse ponto.

\section{Sentido e sofrimento}

A capacidade de realizar um sentido no sofrimento - pelo qual se considera a tríade dor, culpa e morte - é a terceira modalidade de realização de sentido - modalidades inclusivas, nunca exclusivas, importante notar - abordada por Frankl e certamente a mais longamente abordada. Em nosso contexto, é certamente a mais digna de atenção. As outras duas são a realização de sentido através da criação, isto é, através de uma obra, e a realização de sentido através do amor por outro ser humano, isto é, um sentido mediante "o que o homem dá ao mundo" e um sentido mediante o que "o homem recebe do mundo, em termos de encontros e experiências". ${ }^{61}$

Quanto à dor, culpa e morte são casos em que a realização do sentido deixa de depender de uma alteração na situação em que o sujeito se encontra - mudança que é amiúde impossível - e passa a consistir em uma mudança do próprio sujeito. Para tanto, a terminologia usada é valor de atitude. Nesse caso, torna-se mais expressiva do que nunca a atuação de uma liberdade que supera todos os condicionantes, sejam eles biológicos, psicológicos e sociológicos. Radicalmente contrário a todo reducionismo, Frankl faz questão de enfatizar uma liberdade que permanece intocável apesar das mais atrozes condições exteriores, ${ }^{62}$ tal

${ }^{60}$ FRANKL, 2013, p. 73. Cf., ademais, FRANKL, 1992, p. 52: "Porém, dos recônditos de seu 'inconsciente transcendente', esta transcendência reprimida emerge às vezes como 'inquietude do coração', que pode ocasionalmente levar a uma evidente sintomatologia neurótica, isto é, pode manifestar-se como uma neurose".

${ }^{61}$ FRANKL, 2013, p. 90-91. Grifos no original. Cf., ademais, FRANKL, 2008, p. 136.

${ }^{62}$ Cf. FRANKL, 2008, p. 152: "Antes de mais nada, há um perigo inerente na doutrina do 'nada mais que' aplicado à pessoa; a teoria de que o ser humano é 'nada mais que' o resultado de condicionantes biológicos, psicológicos e sociológicos, ou produto da hereditariedade e do meio ambiente. Semelhante visão do ser humano faz o neurótico acreditar no que ele já tende a pensar de qualquer forma, a saber, que é um fantoche, vítima 
como em seu próprio caso como prisioneiro nos campos de concentração nazistas.

A respeito da possibilidade de encontrar um sentido em tais circunstâncias, devemos aqui considerar uma das ideias mais fundamentais para nosso objetivo, a de que para Frankl a descoberta de um sentido no sofrimento, ou seja, os valores de atitude, "constituem os mais altos valores possíveis. O sentido do sofrimento - do inevitável e inescapável sofrimento em si, obviamente - constitui o mais profundo sentido possível". ${ }^{63}$

Frankl insiste que há uma relação de proporção direta entre a dificuldade de encontrar um sentido e a profundidade do sentido a ser encontrado, o que se evidencia na pergunta por um sentido último, conforme veremos adiante. Em situações nas quais há um claro sucesso alcançado - seja no nível da mera satisfação corporal ou de um plano mais elevado, como a conquista de um cargo ou o crescimento de uma família -, o sentido parece estar claramente à vista. Agora, no caso do sofrimento inevitável, a consciência, órgão do sentido, é como que deixada sem o amparo de uma realidade minimamente agradável que quase por si própria responda pela razoabilidade do rumo dos eventos. Nesse caso, portanto, o encontro de um sentido necessariamente ultrapassará toda realidade imediata e, tal como vimos ser o caso de Pascal, não descansará senão no vislumbre de um bem eterno. Uma das ilustrações mais significativas que Frankl fornece a esse respeito - embora, é bom lembrar, "em si mesma, a logoterapia é [seja] uma abordagem laica de problemas clínicos" ${ }^{4}$ - é a de uma paciente de oitenta anos de idade com

de influências externas ou circunstâncias internas. Esse fatalismo neurótico é fomentado e reforçado por uma psicoterapia que nega liberdade à pessoa. Sem dúvida, o ser humano é um ser finito e sua liberdade é restrita. Não se trata de estar livre de fatores condicionantes, mas sim da liberdade de tomar uma posição frente aos condicionamentos". Interessante notar a semelhança com o conceito de vontade em Agostinho, segundo o qual, em poucas palavras, a inversão da ordem interna humana, isto é, o apetite subordinado à razão, seja uma inversão em última instância voluntária, ou seja, antes do ser humano ser dominado por sua animalidade, ele decide livremente por essa dominação, preservada, portanto, a intocabilidade de sua vontade. Que, dada a inversão, já não se possa mais atribuir liberdade ao sujeito desordenado, isso em nada compromete sua responsabilidade última. Em Pascal, essa questão ressurge de maneira bastante clara na discussão do jansenista contra a casuística jesuíta, em especial na IV Provincial. O hábito de pecar em nada diminui a gravidade do pecado, sob a alegação de ausência de força para resistir a ele: "Os pecadores por hábito merecem bem ser chamados, em todo rigor do termo, de "livres pecadores"'. FERREYROLLES, 1995, p. 96. Grifo do autor.

${ }^{63}$ FRANKL, 2013, p. 97.

${ }^{64}$ Ibidem, p. 152. Para mais informações a respeito da relação entre logoterapia e teologia, cf. FRANKL, 1992, p. 59-65. 
um câncer sobre o qual nenhum tratamento teve sucesso. Em vista disso, a pessoa envolvida desenvolveu uma depressão. No início da entrevista, Frankl explicita o fim próximo de tudo o que a paciente experimentou. Há, então, uma primeira reviravolta, quando Frankl procura fazer com que a senhora perceba que ninguém pode apagar as suas conquistas, nem a bondade encontrada ao longo da vida, nem os sofrimentos superados. ${ }^{65}$ Até aqui, aplica-se uma das máximas de Frankl: "Ser-passado é a forma mais segura de ser". ${ }^{66}$

Uma segunda reviravolta - e mais significativa para os nossos propósitos - ocorre quando a senhora revela ter medo de que seu sofrimento seja uma punição divina: "Mas sabe, doutor, eu vejo meu sofrimento como uma punição. Eu acredito em Deus". Ao que Frankl, procurando pôr-se no lugar da paciente, improvisa as seguintes questões: "Mas, será que, às vezes, o sofrimento não é um desafio? Não seria concebível pensar que Deus quis ver como Anastasia Kotek o suportaria? Talvez, devendo até admitir: "é, ela o suportou bravamente"”. E acrescenta, retornando à questão da perpetuidade do passado: "Agora me diga: pode alguém remover tal conquista do mundo, senhora Kotek?" "Certamente, ninguém pode!", ${ }^{67}$ responde a senhora.

Tanto nesse caso como em outros que Frankl relata acerca de uma mudança de postura frente ao fim de uma vida ao qual se acrescente ainda o sofrimento, parece haver uma mudança de compreensão da vida por parte do paciente. Cabe-nos agora, portanto, perguntar o motivo pelo qual Frankl usa para tais circunstâncias a expressão valor de atitude, conforme aludimos acima. Se o curso das coisas não pode ser alterado nesses casos, não seria mais correto falar em compreensão, ao invés de atitude?

Ora, se o sentido mais profundo se descobre em meio a um sofrimento - embora Frankl insista que de modo algum é necessário sofrer para se descobrir um sentido -, a relação mais profunda - devemos dizer, mais íntima - do ser humano com o sentido se dá em uma decisão livre. O sentido deve ser descoberto, mas o sujeito deve decidir-se por ele, mesmo - e talvez principalmente - nos casos em que essa decisão não se reflete em nenhuma mudança perceptível exteriormente. A decisão é, de fato, o critério maior da religiosidade:

\footnotetext{
${ }^{65}$ FRANKL, 2013, p. 152.

${ }^{66}$ Ibidem, p. 150.

${ }^{67}$ Ibidem, p. 152-153.
} 
A verdadeira religiosidade não tem caráter de impulso, mas, antes, de decisão. A religiosidade se mantém pelo seu caráter de decisão, e deixa de ser quando predomina o caráter de impulso. A religiosidade ou é existencial, ou não é nada. ${ }^{68}$

Agora, é na questão de um sentido último, de um suprassentido, que o caráter existencial da religiosidade atinge o seu cume. Para além de todos os sentidos particulares, há um sentido infinito que se dirige para o fundo da personalidade humana, isto é, para o "coração", em termos pascalianos. Resta-nos averiguar esse ponto.

\section{O sentido infinito e a ordem do coração}

Ao se aproximar das questões acerca de um sentido que ultrapasse todos os sentidos particulares, Frankl insiste na ideia de que "quanto mais amplo for o sentido, menos compreensível ele se torna". ${ }^{69}$ Apesar disso, a busca mesma por sentido não se detém nos casos limitados e, portanto, acessíveis a nossa compreensão. A incompreensibilidade detém unicamente a compreensão, nunca a vontade de sentido. O que talvez possa ser considerado como uma das mais fortes evidências para isso são os resultados do próprio Frankl no sentido de que a frustração existencial se encontra abundantemente em meio ao sucesso profissional ou à alta qualidade de vida..$^{70}$ Acrescentem-se a isso os inúmeros casos de felicidade nos meios mais adversos. ${ }^{71}$

A tensão que agora queremos explicitar é a que há entre uma questão que ultrapassa infinitamente a compreensão humana, isto é, a de um sentido infinito, e o fato de que é justamente essa a questão mais decisiva para o ser humano. Se levarmos em conta que Pascal nunca desassocia o problema da existência de Deus do problema da imortalidade da alma, ${ }^{72}$ então vale chamar atenção que para o jansenista "a imortalidade da alma é uma coisa que nos importa tanto, que nos toca tão profundamente, que é necessário ter perdido todo sentimento para estar indiferente quanto a saber qual o caso". Entretanto, por mais

\footnotetext{
${ }_{68}$ FRANKL, 1992, p. 50.

${ }^{69}$ FRANKL, 1992, p. 90. Grifos no original.

${ }^{70}$ Cf., por exemplo, FRANKL, 2008, p. 125 e 131. E também FRANKL, Um sentido para a vida: psicoterapia e humanismo. Aparecida: Editora Santuário, 1989, p. 27.

${ }^{71}$ Cf. FRANKL, 1989, p. 15, onde é citado o depoimento de um prisioneiro americano, Cleve W.: “Aqui na prisão... há muitas e muito agradáveis ocasiões de ser útil e de crescer. Na realidade sou mais útil agora do que em qualquer outra ocasião".

${ }^{72}$ Cf. RUSSIER, 1949, p. 70.
} 
importante que seja tal questão, a compreensão humana não tende para nenhum lado: "Incompreensível que Deus exista e incompreensível que Ele não exista, que a alma exista com o corpo, que nós não tenhamos alma $[\ldots]^{\prime \prime} \cdot{ }^{73}$

O passo mais decisivo a respeito de tal tensão entre a finitude da ordem do espírito e a infinidade da ordem da vontade está na consideração de que o incompreensível, embora não possa ser objeto de demonstração, pode ser objeto de crença, e, mais ainda, da crença mais decisiva da vida humana, que é a crença em um sentido da vida humana. Uma das formas de se compreender que "o homem ultrapassa infinitamente o homem"74 é que se pode acreditar no incompreensível, ideia que se encontra de maneira praticamente idêntica em Pascal e Frankl. ${ }^{75}$

Devemos acentuar o caráter de decisão que envolve a crença em um sentido último de toda a existência:

De fato, é impossível descobrir apenas pelo intelecto se, em última análise, tudo é desprovido de sentido, ou se existe um sentido encoberto por detrás de tudo. Embora não haja uma resposta intelectual a esta pergunta, é possível assumir diante dela uma decisão existencial. Diante do fato de que é igualmente concebível que tudo tenha um sentido, e que tudo seja desprovido de sentido, ou seja, que os argumentos pró ou contra um último sentido se mantenham equilibrados nos pratos da balança, podemos jogar o peso de nosso próprio ser no prato a favor do sentido, decidindo-nos por uma das duas possibilidades de pensamento. ${ }^{76}$

Agora, para que essa decisão tenha ela mesma algum efeito sobre a vida do sujeito que decide, é preciso que, à advertência da diferença entre incompreensível e inacreditável, some-se a advertência de que a ausência de relação entre homem e Deus se restrinja à segunda ordem. À ordem racional, que se aniquila ao não admitir os seus limites, como procuramos expor no início, contrapõe-se uma "faculdade de desproporção", ${ }^{77}$ ou do "claro-obscuro", ${ }^{78}$ qual seja, a ordem do coração,

\footnotetext{
${ }^{73}$ Laf. 809.

${ }^{74}$ Laf. 131.

${ }^{75}$ FRANKL, 1992, p. 90: “o que é incompreensível não precisa necessariamente ser inacreditável”. E, em Pascal, Laf. "Nem tudo o que é incompreensível deixa de existir".

${ }^{76}$ Ibidem, p. 84. Cf. também a nota (p. 91) que Frankl escreve a respeito dessa passagem: "Não é a partir de uma lei lógica, mas apenas a partir da profundeza de seu próprio ser que o homem consegue tomar essa decisão, consegue decidir-se por um ou outro caminho".

77 Cf. MICHON, 1996, p. 286.

${ }^{78}$ Ibidem, p. 288.
} 
cujo alvo próprio é Deus, ainda que esse alvo se apresente sob a forma de desejo. Aqui, a autotranscendência humana conhece o seu maior nível, o da alma que, reconhecendo "por uma luz toda pura" que o "soberano bem" não está nas coisas que estão nela, nem fora dela, nem diante dela, começa a procurar acima dela". ${ }^{79}$ Se há um sentido último a ser buscado, a autotranscendência é tanto mais excelente quanto consistir na abertura para esse sentido último, a tal ponto que a alma "se aniquila em sua presença". ${ }^{80}$ Trata-se de uma entrega total, de uma abdicação decisiva de estabelecer em si mesma a sua identidade. É a transcendência própria de um ser produzido unicamente para o infinito.

Não poderíamos deixar de citar aqui uma passagem na qual Frankl se vale do próprio Pascal para explicar em que consiste a relação entre a limitação da compreensão humana e a questão de um sentido último:

Quanto mais abrangente for um sentido, mais difícil será apreendêlo. O sentido infinito nem está ao alcance da compreensão de um ente finito. Neste ponto a ciência desiste e a sabedoria toma a palavra, a sabedoria do coração, da qual Blaise Pascal afirmou certa vez: "O coração tem razões que a razão não conhece". Mesmo o salmista fala de uma sapientia cordis (Salmo 89).

De fato, o coração em Pascal também tem a sua função cognitiva, mais propriamente compreendida como intuição. Trata-se, porém, em oposição à razão, de uma apreensão incompleta, um meio termo entre a ausência e a presença, meio termo que permite justamente o desejo e a busca - mas que permite também a "confusão" de amar infinitamente o finito. Se o sentido de nossa existência não está totalmente ausente nem totalmente presente, é justamente isso que nos permite perguntar por ele, buscar por ele, e nos enganar quanto a ele. Essa última hipótese, porém, é ainda melhor do que a de não investigar nada a esse respeito, que é a hipótese que entendemos sera apatia sobrenatural da qual falamos no início.

A intuição à qual nos referimos é ilustrada diversas vezes por Frankl mediante a novela de Tolstói intitulada A morte de Ivan Ilitch, na qual se narra o que se pode descrever como a descoberta de um sentido após uma vida apática para tudo o que transcendesse as conveniências sociais mais imediatas. Quando a morte se torna iminente, há uma reviravolta que Frankl assim descreve:

\footnotetext{
79 Sur la conversion du pécheur. PASCAL, 1963, p. 291.

${ }^{80}$ Ibidem, p. 291. A respeito da abertura em Frankl, bem como do perigo de se encerrar o ser humano em processos de condicionamento, cf. FRANKL, 1989, p. 47-48.
} 
Mas por uma intuição ele percebe, não apenas ao confrontar a morte, mas ao dar-se conta de que havia desperdiçado a vida, que sua existência fora praticamente sem sentido - por esta intuição ele se eleva acima de si mesmo, cresce para além de si e assim finalmente é capaz de retroativamente encher a própria vida com um sentido infinito. ${ }^{81}$

Não poderíamos exigir mais conformidade com a alma que suplica: “[...] tendo vivido na amargura de meus pecados durante a paz, [que] eu aprecie as doçuras celestes de Vossa graça durante os males salutares com os quais Vós me afligis". ${ }^{82}$

\section{Conclusão}

A busca firmemente decidida, uma busca de todo coração, por um Deus absconditus, no qual se completa o sentido último da existência, é a expressão mais perfeita da imperfeição humana: a imperfeição de um ser cujo repouso está em um Deus que, ainda que rejeitado, inquieta o coração humano. Essa inquietude, por sua vez, em vista da falta de clareza de sua origem, pode tanto resultar na busca por sentido quanto na caça de uma lebre.

Ora, nem uma das duas buscas será plenamente satisfeita. O caçador logo se entediará quando alcançar a lebre e, então, partirá atrás de outra, uma vez que o que ele busca é a própria busca que por definição não se pode alcançar. O homem que busca Deus, por sua vez, tampouco poderá possuí-Lo completamente. Mas, é essa impossibilidade mesma que decide a diferença entre os dois casos: no primeiro, uma busca fracassada por um objeto impróprio à vontade que busca; no segundo, uma busca eternamente realizada pelo único ser que corresponde à vontade infinita que o busca. Nos dois casos, o homem transcende a si próprio, com a diferença de que apenas no segundo essa transcendência é uma abertura para sua identidade última, uma decisão conforme a um ser consciente de sua vida finita e desejoso de um sentido infinito. Diante desse último, porém, a finitude mesma do homem já se transfigura face à eternidade que a precede e que aguarda a sua decisão, a qual não poderá consistir no resultado de um exercício da razão, mas somente em um ato de fé: "Não conseguimos relacionar-nos com esse suprassentido em solo puramente racional, mas, apenas, em solo existencial, através de

\footnotetext{
${ }^{81}$ FRANKL, 1989, p. 84.

82 Prière pour demander a Dieu le bon usage des maladies. PASCAL, 1963, p. 362.
} 
todo nosso ser, isto é, por meio da fé". 83 "Através de todo nosso ser", quer dizer, do mais profundo de nossa personalidade: ${ }^{84}$ uma decisão por Aquele que quer ser descoberto por aqueles "que o procuram de todo o coração". 85

\section{Referências}

FERREYROLLES, Gérard. Les Reines du monde: l'imagination et la coutume chez Pascal. Paris: Honoré Champion Éditeur, 1995.

FRANKL, Viktor. A presença ignorada de Deus. 7. ed. São Leopoldo: Sinodal; Petrópolis: Vozes, 1992.

. A vontade de sentido: fundamentos e aplicações da logoterapia. 2. ed. São Paulo: Paulus, 2013.

. Em busca de sentido. Um psicólogo no campo de concentração. 25. ed. São Leopoldo: Sinodal; Petrópolis: Vozes, 2008.

. Um sentido para a vida: psicoterapia e humanismo. Aparecida: Editora Santuário, 1989.

MICHON, H. L'ordre du coeur: philosophie, théologie et mystique dans les Pensées de Pascal. Paris: Honoré Champion, 1996.

PASCAL, Blaise. Oeuvres complètes. Organização por Louis Lafuma. Paris: Seuil, 1963.

. Pensamentos. São Paulo: Difusão Europeia do Livro, 1961.

PONDÉ, L. F. O homem insuficiente: comentários da antropologia pascaliana. São Paulo: EDUSP, 2001.

PETER, Ricardo. Viktor Frankl: a antropologia como terapia. São Paulo: Paulus, 1999.

RUSSIER, J. La foi selon Pascal: Dieu sensible au coeur. Paris: PUF, 1949.

Recebido: 18/07/2014

Avaliado: $25 / 07 / 2014$

${ }_{83}$ FRANKL, 2013, p. 181.

${ }^{84}$ A respeito da relação entre coração e fundo do ser humano, cf. RUSSIER, 1949, p. 156.

${ }^{85}$ Laf. 149. Cf. também MICHON, 1996, p. 288: "Pascal privilegia de tal modo este ponto que a fé se torna para ele um ato essencialmente devido à vontade: ela pode mesmo ser definida como o desejo de Deus, pois ela é uma tensão para Aquele que não é nem totalmente presente nem totalmente ausente". 